Randomized Control Trial

\title{
e Whole-Course Application of Dexmedetomidine Combined with Ketorolac in Nonnarcotic Postoperative Analgesia for Patients with Lung Cancer Undergoing Thoracoscopic Surgery: A Randomized Control Trial
}

Qing-ping Wen, PhD, Zhuang Miao, $\mathrm{MD}^{1}$, Ping $W \mathrm{u}^{\mathrm{N}} \mathrm{MD^{1 }}$, Jing Wang, $\mathrm{MD}^{2}$, Fa-chen Zhou, MD³, Yun Lin, MD², Xin-yu Lu, MD'1, Run Lv, MD², and Qian-hao Hou, MD²

From: ${ }^{2}$ Department of Anesthesiology, The First Affiliated Hospital of Dalian Medical University, Dalian, China; ${ }^{2}$ Anesthesiology Department, Dalian Medical of University, Dalian, China; ${ }^{3}$ Department of Thoracic Surgery,

The First Affiliated Hospital of Dalian Medical University, Dalian, China

Address Correspondence: Qing-ping Wen, PhD No.193 Lianhe Road, Xigang District, Dalian City, Liaoning Province, China E-mail: wenqingping18098877988@ hotmail.com

Disclaimer: This study was supported, in part, by grants

from the Natural Science

Foundation of Liaoning (20170540290, 20180551083). Conflict of interest: Each author certifies that he or she, or a member of his or her immediate

family, has no commercial association (i.e., consultancies, stock ownership, equity interest, patent/licensing arrangements, etc.) that might pose a conflict of interest in connection with the submitted manuscript.

Manuscript received: 06-16-2019 Revised manuscript received: o9-24-2019

Accepted for publication: 10-03-2019

Free full manuscript: www.painphysicianjournal.com
Background: Opioid-based postoperative analgesia provides adequate analgesia with much adverse effects and immunosuppression. Dexmedetomidine and ketorolac have properties of opioid-sparing, antiinflammation, and immune protection.

Objectives: To investigate the efficacy and safety of whole-course application of dexmedetomidine combined with ketorolac in nonnarcotic postoperative analgesia and its effect on inflammatory response and immune function in thoracoscopic surgery of lung cancer.

Study Design: Double-blind, randomized control trial.

Setting: The First Affiliated Hospital of Dalian Medical University, Dalian, Liaoning, China.

Methods: Sixty patients scheduled for thoracoscopic surgery were enrolled and randomly divided into 2 groups to receive a combination of intraoperative usage of dexmedetomidine and postoperative patient-controlled intravenous analgesia of dexmedetomidine $0.1 \mu \mathrm{g} / \mathrm{kg} / \mathrm{h}$ and ketorolac $3 \mathrm{mg} / \mathrm{kg}$ (DEX group) or only postoperative patient-controlled intravenous analgesia of sufentanil $1.5 \mu \mathrm{g} / \mathrm{kg}$ and ketorolac $3 \mathrm{mg} / \mathrm{kg}$ (SUF group) for 48 hours. Vital signs, postoperative Visual Analog Scale (VAS) score, Ramsay sedation score, patient-controlled analgesia pressing times, consumption of sufentanil and rescue drug, and complications were compared between the 2 groups. The levels of inflammatory factors and immune function were also compared.

Results: A significant reduction in median blood pressures and heart rates within 48 hours after surgery and perioperative consumption of sufentanil were observed in the DEX group compared with the SUF group $(P<0.05)$. No statistically significant difference was found in VAS scores, patient-controlled analgesia pressing times, and rescue drug consumption between the 2 groups ( $P$ $>0.05)$. The incidence of nausea was significantly lower in the DEX group compared with the SUF group $(P<0.05)$. A significant decrease of interleukin (IL)-1 $\beta, \mathrm{IL}-6$, tumor necrosis factor (TNF)- $\alpha$, and increased $\mathrm{CD}^{+}$and $\mathrm{CD} 4^{+} / \mathrm{CD}^{+}$were observed in the DEX group compared with the SUF group at 24 and 48 hours after surgery $(P<0.05)$. There was no difference in the levels of CD $8^{+}$ and natural killer cells between the 2 groups $(P>0.05)$.

Limitations: This study was limited by its sample size.

Conclusions: Whole-course application of dexmedetomidine combined with ketorolac in nonnarcotic postoperative analgesia provided adequate and safe postoperative analgesia, reduced sufentanil consumption, analgesia-related complications, alleviated inflammatory response, and immunosuppression compared with sufentanil-based analgesia in thoracoscopic surgery.

Key words: Dexmedetomidine, ketorolac, sufentanil, thoracoscopic surgery, postoperative analgesic, patient-controlled analgesia, inflammatory response, immune function

Pain Physician 2020: 23:E185-E193 
urrently, thoracoscopic surgery (TSS) has become the optimal choice to treat stage I-II nonsmall cell lung carcinoma (NSCLC) (1). However, patients undergoing thoracoscopic or thoracotomy surgery experience moderate to severe postoperative pain resulting in inflammatory reaction and immunosuppression (2). Also, ischemia-reperfusion injury (IRI) caused by one-lung ventilation (OLV) stimulates the inflammatory response and worsens the immune function (3).

Opioids usually result in dose-related complications, moreover immunosuppression leading to postoperative cancer recurrence (4). Nonnarcotic analgesics can reduce opioids consumption to reduce opioid-related complications and immunosuppression (5).

Dexmedetomidine (DEX) is a highly selective alpha-2 adrenergic receptor agonist that has sedative, analgesic, antisympathetic, and anesthetics-sparing properties, perioperative antiinflammatory effect, especially on IRI in lung surgery, and moreover immunoprotective effects (3,6-7).

Ketorolac (KET), a nonsteroidal antiinflammatory drug (NSAID), has been proved to have antiinflammation and opioid-sparing properties with fewer complications $(8,9)$.

This study aims to investigate the efficacy and safety of the whole-course application of DEX combined with KET in postoperative analgesia, and its effect on inflammatory response and immune function of patients undergoing TSS.

\section{Methods}

\section{Inclusion and Exclusion Criteria}

This study was approved by the ethics committee of the First Affiliated Hospital of Dalian Medical University. The clinical trial registration number is ChicTR1800019796. Sixty patients with lung cancer (clinical stage I-II NSCLC) who were scheduled for TSS from December 2018 to May 2019 were recruited. Written informed consent was obtained after providing patients with adequate explanations regarding the aims of the study. The inclusion criteria were as follows: American Society of Anesthesiologist (ASA) Physical Status score I to II, ages 18 to 65 years, and body mass index (BMI) < $30 \mathrm{~kg} / \mathrm{m}^{2}$. The exclusion criteria were as follows: history of radiotherapy-chemotherapy, immune disorders, hepatic or renal dysfunction, bradycardia (heart rate [HR] $<45$ bpm), gastrointestinal (GI) ulcer or bleeding, and relevant drug allergy.

\section{Randomization}

Enrolled patients were randomly assigned according to computer-generated random assignment to receive a combination of intraoperative usage of DEX and postoperative patient-controlled intravenous analgesia (PCIA) of DEX $0.1 \mu \mathrm{g} / \mathrm{kg} / \mathrm{h}$ and KET $3 \mathrm{mg} / \mathrm{kg}$ (DEX group), or only postoperative PCIA of sufentanil (SUF) $1.5 \mu \mathrm{g} / \mathrm{kg}$ and KET $3 \mathrm{mg} / \mathrm{kg}$ (SUF group) for 48 hours. The persons involved in the study, including statisticians, investigators, anesthesiologists, surgeons, and the patients, were blinded to the specific experimental scheme implementation.

\section{Anesthesia Protocol}

The vital signs, such as blood pressure, HR, pulse oxygen saturation, respiratory rates, and partial pressure of end-tidal $\mathrm{CO}_{2}\left(\mathrm{P}_{\mathrm{ET}} \mathrm{CO}_{2}\right)$ were recorded. In the DEX group, a bolus intravenously infusion of $1 \mu \mathrm{g} / \mathrm{kg}$ DEX was given over 10 minutes before anesthesia induction, followed by a continuous infusion at a rate of $0.4 \mu \mathrm{g} /$ $\mathrm{kg} / \mathrm{h}$ until 30 minutes before the end of the surgery, whereas a placebo infusion of the same amount of normal saline solution was administered in the SUF group. In both groups, anesthesia was induced with $2 \mathrm{mg} / \mathrm{kg}$ propofol, 0.3 to $0.5 \mu \mathrm{g} / \mathrm{kg} \mathrm{SUF}$, and 0.2 to $0.3 \mathrm{mg} / \mathrm{kg}$ cisatracurium.

Anesthesia was maintained with propofol 2 to 4 $\mathrm{mg} / \mathrm{kg} / \mathrm{h}$, remifentanil 0.1 to $0.2 \mu \mathrm{g} / \mathrm{kg} / \mathrm{min}$, and cisatracurium 0.1 to $0.15 \mathrm{mg} / \mathrm{kg} / \mathrm{h}$ to maintain a bispectral index of 45 to 60 .

The double-lumen tube was located with a fibrous bronchoscope, and ventilation parameters were modulated to maintain $\mathrm{P}_{\mathrm{ET}} \mathrm{CO}_{2}$ of 35 to $45 \mathrm{~mm} \mathrm{Hg}$. At the end of surgery, the intercostal nerve block was done with $20 \mathrm{~mL} 0.5 \%$ ropivacaine by the same surgeon. After surgery, the patients were extubated and transmitted to the postanesthesia care unit. A dose of $5 \mu \mathrm{g}$ SUF was administered per time when Visual Analog Scale (VAS) score $>3$, until VAS $\leq 3$.

\section{Postoperative Analgesia}

PCIA protocols within 48 hours after surgery were as follows: in the DEX group, $0.1 \mu \mathrm{g} / \mathrm{kg} / \mathrm{h}$ DEX, $3 \mathrm{mg} /$ $\mathrm{kg} \mathrm{KET}$, and $0.5 \mathrm{mg}$ palonosetron; in the SUF group, 1.5 $\mu \mathrm{g} / \mathrm{kg}$ SUF, $3 \mathrm{mg} / \mathrm{kg} \mathrm{KET}$, and $0.5 \mathrm{mg}$ palonosetron were diluted in $100 \mathrm{~mL}$ normal saline solution. The infusion rate of $2 \mathrm{~mL} / \mathrm{h}$, a bolus dose of $2 \mathrm{~mL}$, and lockout time 20 minutes were set. A rescue analgesic of tramadol was given when VAS score $>4$. 


\section{Indicators}

\section{Hemodynamic Indicators}

Mean blood pressures (MAPs) and HRs were recorded before induction $\left(T_{0}\right)$, immediately after surgery $\left(T_{1}\right)$, 4 hours $\left(T_{2}\right), 12$ hours $\left(T_{3}\right), 24$ hours $\left(T_{4}\right)$, and 48 hours after surgery $\left(\mathrm{T}_{5}\right)$.

\section{Analgesic and Sedative Indices}

The resting and coughing VAS $(0-10 ; 0=$ no pain, $10=$ the worst pain imaginable) and Ramsay sedation score (RSS) $(1-6 ; 1=$ anxious and agitated, $2=$ cooperative, tranquil, oriented, $3=$ responds only to verbal commands, $4=$ asleep with brisk response to light stimulation, $5=$ asleep without response to light stimulation, 6 $=$ nonresponsive) at $\mathrm{T}_{0}-\mathrm{T}_{5}$ were recorded. The total and valid PCIA pressing times, the consumption of SUF and tramadol, and analgesia-related complications within 48 hours after surgery were recorded.

\section{Inflammatory and Immune Indicators}

A $5 \mathrm{~mL}$ sample of peripheral blood were extracted at $\mathrm{T}_{0}, \mathrm{~T}_{1}, \mathrm{~T}_{4^{\prime}} \mathrm{T}_{5^{\prime}}$ and centrifuged at $3000 \mathrm{rpm}$ for $10 \mathrm{~min}$ utes at $4^{\circ} \mathrm{C}$ to obtain the supernatant, which was later preserved at $-80^{\circ} \mathrm{C}$ for detection. Serum concentrations of interleukin (IL)-1 $\beta, \mathrm{IL}-6$, and tumor necrosis factor (TNF)- $\alpha$ were measured by enzyme-linked immunosorbent assay as described by the manufacturer (R\&D Systems, Inc., Minneapolis, MN), and the levels of T lymphocyte subgroups and natural killer (NK) cells were measured through immunofluorescence staining using multitest labeled antibodies.

\section{Statistical Analyses}

A pilot study was performed prior to patient recruitment to estimate an appropriate sample size. The pilot study included 20 patients, 10 in each arm. We calculated the primary outcome of the study assessed by $\mathrm{CD}^{+} / \mathrm{CD}^{+}$. The sample size of 23 patients in each group provided $\alpha=0.05,90 \%$ power, and an allocation ratio $=$ 1.0. Considering potential drop-outs, we decided to enroll 30 patients in each group for the study. The sample calculation was performed with PASS version 11.0 (PASS 11.NCSS, LLC. Kaysville, UT).

Statistical analysis was performed using SPSS 25.0 statistical software (IBM Corporation, Armonk, NY). Data were expressed as mean \pm standard deviation or median (interquartile range). The Fisher exact test or the chi-square test was employed to analyze dichoto- mous data, the Student t-test was used for normally distributed continuous data, and the Mann-Whitney $U$ test was used for nonparametric ordinal data. Analysis of variance for repeated measurements was performed to analyze differences in means between and within the groups. $P<0.05$ was considered to indicate a statistically significant difference.

\section{Results}

Sixty patients were recruited by the inclusion criteria. However, 6 patients were subsequently excluded: 3 patients refused to participate, 1 patient changed to thoracic surgery, and 2 in the DEX group were lost to follow-up. Total 26 patients in the DEX group and 28 patients in the SUF group completed the study (Fig. 1). There was no significant difference between groups regarding baseline characteristics $(P>0.05)$; intraoperative profiles, such as surgical type, anesthesia, and operation duration; OLV duration; estimated blood loss; and fluid infusion $(P>0.05)$ (Table 1). SUF dosages in the DEX group was significantly lower than the SUF group $(124.23 \pm 14.81 \mu \mathrm{g}$ vs. $234.64 \pm 23.37 \mu \mathrm{g} ; P<0.05)$ (Table 1).

Regarding the hemodynamic indicators, MAPs and HRs in the DEX group were relatively lower than in the SUF group at $\mathrm{T}_{1}-\mathrm{T}_{5}(P<0.05)$ (Fig. 2).

There was no statistical difference in the resting and coughing VAS scores and PCIA pressing times between the 2 groups $(P>0.05$ ) (Table 2). RSS in the DEX group was significantly higher at $\mathrm{T}_{1}-\mathrm{T}_{3}$ than the SUF group $(P<0.05)$ (Table 3$)$. Although the incidence of total analgesic-related complications and nausea in the DEX group were statistically lower than the SUF group $(P<0.05)$ (Table 3). There was one transient hypotension needed to deal with in the DEX group. The incidence of vomiting and pruritus did not differ between the 2 groups, and no respiratory depression or oversedation was observed (Table 3).

The baseline immune function was comparable in the 2 groups $(P>0.05)$. Compared with $T_{0}$, the expression levels of $\mathrm{CD}^{+}, \mathrm{CD} 4^{+} / \mathrm{CD} 8^{+}$, and $\mathrm{CD} 3^{+}$in both groups decreased significantly to the lowest point at $T_{1}(P<$ $0.05)$ and began to increase from $T_{4}$, which was still significantly lower $(P<0.05)$. Compared with the DEX group, the levels of $\mathrm{CD}_{4}^{+}, \mathrm{CD}^{+} / \mathrm{CD}^{+}$, and $\mathrm{CD}^{+}$in the SUF group were significantly lower at $\mathrm{T}_{4}$ and $\mathrm{T}_{5}(P<$ $0.05)$. No significant difference was found in the level of $\mathrm{CD}^{+}$between the 2 groups at any time point $(P>$ $0.05)$. The level of NK cells at $T_{1}$ was significantly higher 


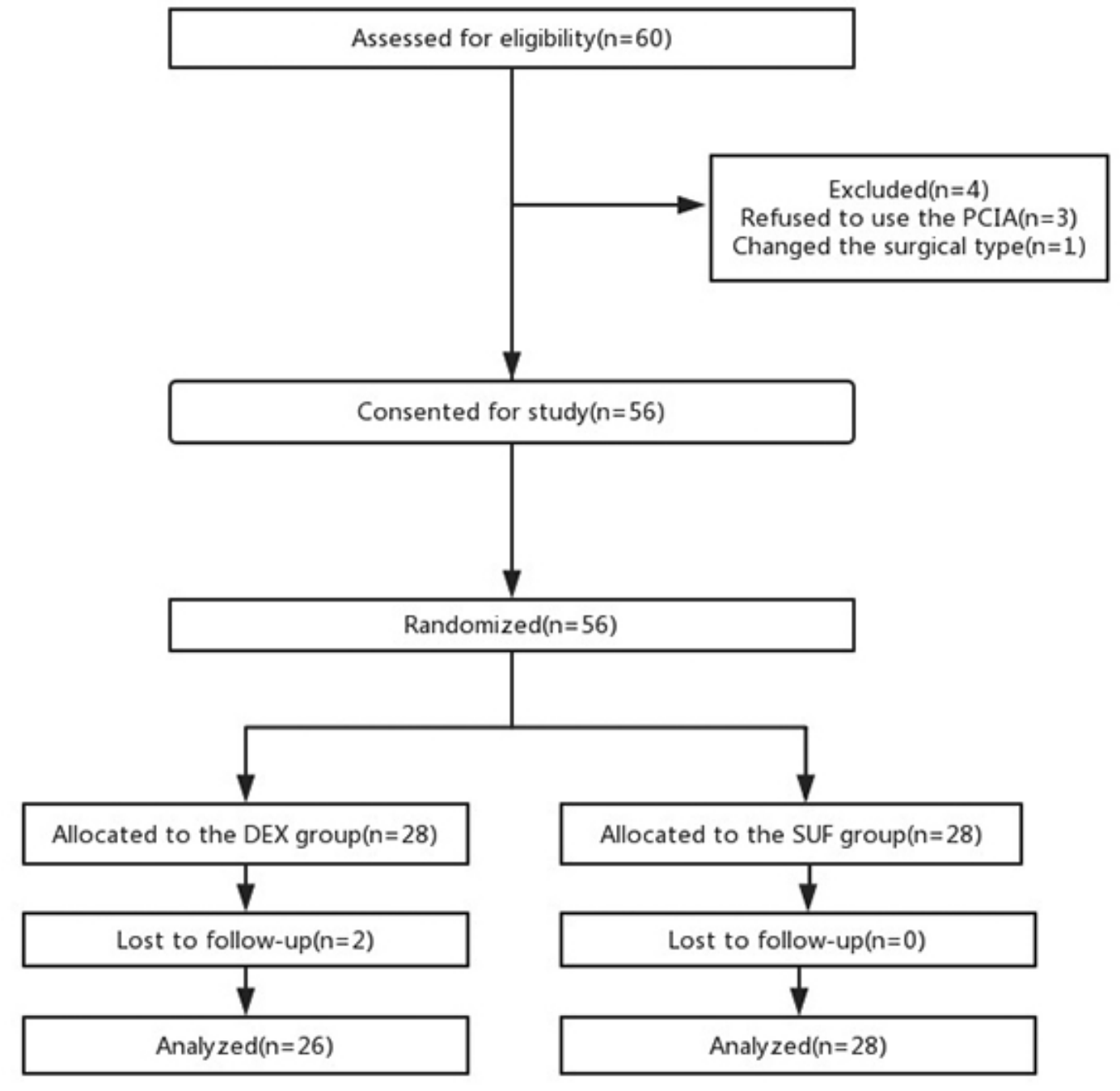

Fig. 1. Flow chart of study inclusion.

than at $\mathrm{T}_{0}$ in the 2 groups $(P<0.05)$, whereas no significant differences were found between the 2 groups at any time point $(P>0.05)$ (Table 4, Fig. 3 ).

The preoperative inflammatory response was also comparable in the 2 groups $(P>0.05)$. Compared with $\mathrm{T}_{0}$, the levels of IL-1 $\beta, \mathrm{IL}-6$, and TNF- $\alpha$ were remarkably elevated at $T_{1}, T_{4}$, and $T_{5}$, and the amplitude in the SUF group was significantly higher than the DEX group $(P<$ 0.05) (Fig. 4).

It is therefore of great benefit for the patients' outcome if surgical trauma is minimized, adequate postoperative analgesia is achieved with a minimum dose of opioids, and inflammatory response caused by OLV is decreased.

\section{Discussion}

Patients undergoing TSS usually suffer postoperative immunosuppression, which results from the lung cancer itself, surgical trauma, usage of opioids, and postoperative pain (10). Trauma, pain, and OLV during TSS also induce inflammatory responses, which worsen the immune function $(2,3)$, increase the implantation of surgically disseminated tumor cells and the growth of existing micrometastases $(4,11)$. 
Table 1. Patient characteristics and intraoperative data.

\begin{tabular}{|c|c|c|c|}
\hline & SUF group & DEX group & $P$ value \\
\hline Number & 28 & 26 & \\
\hline Demographics & & & $>0.05$ \\
\hline Gender $\mathrm{n} / \mathrm{N}$ (\% female) & $11 / 28(39)$ & $10 / 26(38)$ & .. \\
\hline Age, years & $58 \pm 6$ & $54 \pm 10$ & .. \\
\hline $\mathrm{BMl} \mathrm{kg} / \mathrm{m}^{2}$ & $22.8 \pm 1.1$ & $22.8 \pm 0.9$ & .. \\
\hline ASA group, n/N(\%) & & & .. \\
\hline Gr oup I & $1 / 28(4)$ & $2 / 26(8)$ & \\
\hline Group II & $27 / 28(96)$ & $23 / 26(92)$ & \\
\hline \multicolumn{4}{|l|}{ Intraoperaive profiles } \\
\hline Surgical type n/N(\% lobectomy) & $28 / 28(100)$ & $26 / 26(100)$ & 1.000 \\
\hline Anesthesia time(min) & $172.39 \pm 25.05$ & $172.00 \pm 20.49$ & 0.950 \\
\hline Operation time(min) & $139.57 \pm 24.06$ & $144.42 \pm 19.38$ & 0.420 \\
\hline OLV time(min) & $111.29 \pm 23.37$ & $118.62 \pm 20.71$ & 0.229 \\
\hline Blood loss $(\mathrm{mL})$ & $43.04 \pm 8.90$ & $46.35 \pm 11.06$ & 0.230 \\
\hline Fluid amount $(\mathrm{mL})$ & $1250.00(1000.00 \sim 1250.00)$ & $1250.00(1000.00 \sim 1250.00)$ & 0.539 \\
\hline \multicolumn{4}{|l|}{ Sufentanil consumption(ug) } \\
\hline During operation & $132.14 \pm 13.71$ & $124.23 \pm 14.81$ & 0.047 \\
\hline Perioperatlve & $234.64 \pm 23.37$ & $124.23 \pm 14.81$ & 0.000 \\
\hline
\end{tabular}

Data are presented as mean \pm standard deviatic or mean (interquartile range); $\mathrm{n} / \mathrm{N}$ is number with the characteristic/total number. BMI, body mass index; ASA, American Society of Anesthesiology physical statues classification system,range 1 (normal) to 5 (moribund); OLV, one-lung ventilation.

Table 2. VAS scores and PCIA pressing times.

\begin{tabular}{|c|c|c|}
\hline & SUF group & $\overline{\text { DEX group }}$ \\
\hline \multicolumn{3}{|l|}{ R-VAS } \\
\hline \multicolumn{3}{|l|}{$\mathrm{T}_{0}$} \\
\hline $\mathrm{T}_{1}$ & $1(0-1)$ & $0(0-1)$ \\
\hline $\mathrm{T}_{2}$ & $1(0-2)$ & $0.5(0-1)$ \\
\hline $\mathrm{T}_{3}$ & $1(1-2)$ & $1(0-2)$ \\
\hline $\mathrm{T}_{4}$ & $2(2-3)$ & $2(1-2.25)$ \\
\hline $\mathrm{T}_{5}$ & $1(1-1.75)$ & $1(0-1)$ \\
\hline \multicolumn{3}{|l|}{ C-VAS } \\
\hline $\mathrm{T}_{0}$ & 0 & 0 \\
\hline $\mathrm{T}_{1}$ & $2(1-2)$ & $1(1-2)$ \\
\hline $\mathrm{T}_{2}$ & $2(1-3)$ & $1.5(1-2)$ \\
\hline $\mathrm{T}_{3}$ & $2(2-3)$ & $2(1-3)$ \\
\hline $\mathrm{T}_{4}$ & $3(2-3)$ & $3(2.75-3.25)$ \\
\hline $\mathrm{T}_{5}$ & $2(2-3)$ & $2(2-2.25)$ \\
\hline \multicolumn{3}{|l|}{ PCIA pressing times } \\
\hline Valid times & $4(2-6)$ & $3.5(1-5.25)$ \\
\hline Total times & $5(2-6.75)$ & $4(1-7)$ \\
\hline
\end{tabular}

R-VAS, resting VAS scores; C-VAS, coughing VAS scores; PCIA, patient-controlled intravenous analgesia.
Table 3. Main adverse events, rescue analgesic requirements and Ramsay scores.

\begin{tabular}{|l|c|c||}
\hline & SUF group & DEX group \\
\hline Number & 28 & 26 \\
\hline Adverse events & & \\
\hline Nausea & $11(39)$ & $2(8)^{*}$ \\
\hline Vomit & $3(11)$ & 0 \\
\hline Pruritus & $3(11)$ & $1(4)$ \\
\hline Hypotension & 0 & $1(4)$ \\
\hline Respiratory depression & 0 & 0 \\
\hline Total & $17(61)$ & $4(15)^{\star}$ \\
\hline Rescue analgesia & $4(14)$ & $5(19)$ \\
\hline Sedation $(1 / 2 / 3 / 4 / 5 / 6)$ & & \\
\hline $\mathrm{T}_{0}$ & $9 / 19 / 0 / 0 / 0 / 0$ & $8 / 18 / 0 / 0 / 0 / 0$ \\
\hline $\mathrm{T}_{1}$ & $14 / 10 / 4 / 0 / 0 / 0$ & $4 / 8 / 14 / 0 / 0 / 0^{*}$ \\
\hline $\mathrm{T}_{2}$ & $0 / 21 / 7 / 0 / 0 / 0$ & $0 / 11 / 9 / 6 / 0 / 0^{*}$ \\
\hline $\mathrm{T}_{3}$ & $0 / 19 / 7 / 2 / 0 / 0$ & $0 / 10 / 10 / 6 / 0 / 0^{*}$ \\
\hline $\mathrm{T}_{4}$ & $0 / 19 / 8 / 1 / 0 / 0$ & $0 / 15 / 7 / 4 / 0 / 0$ \\
\hline $\mathrm{T}_{5}$ & $0 / 16 / 11 / 1 / 0 / 0$ & $0 / 12 / 9 / 5 / 0 / 0$ \\
\hline
\end{tabular}

Data are number of patients or\%. ${ }^{\star} P<0.05$, SUF group vs DEX group. 

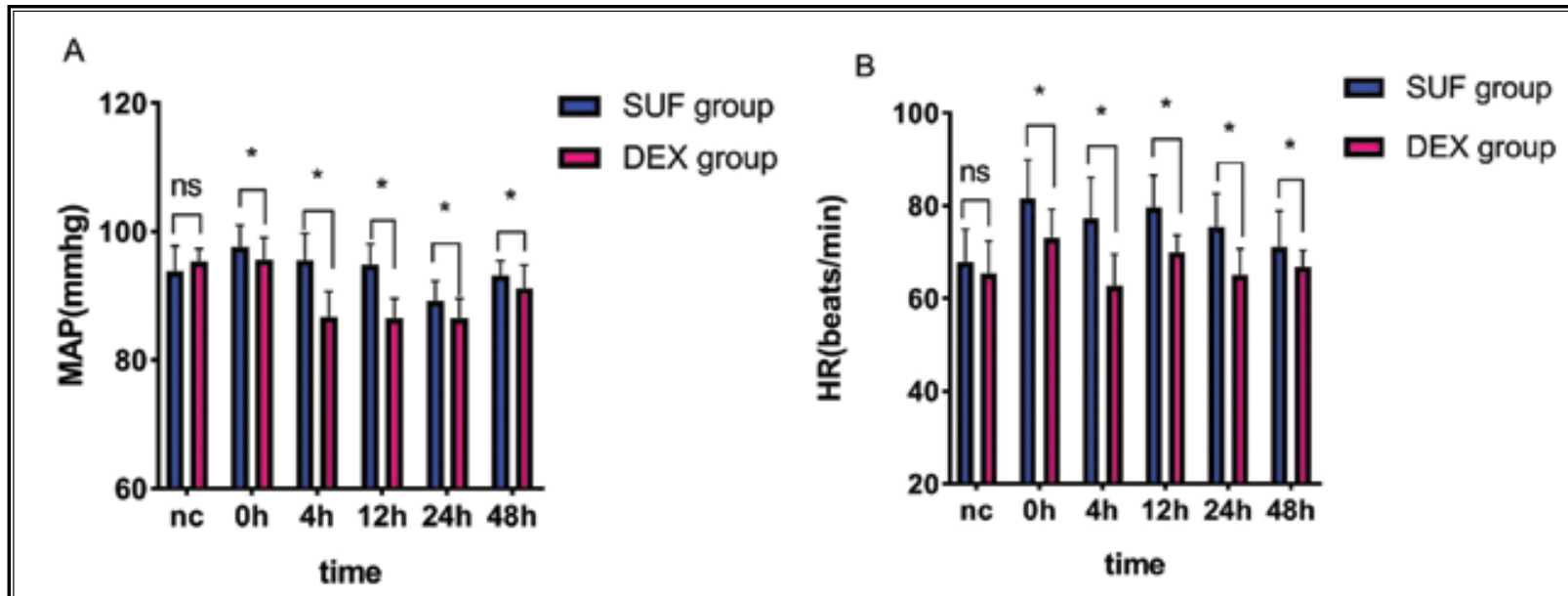

Fig. 2. Differences in (A) MAP and (B) HR between the 2 groups. ${ }^{*} P<0.05$ vs. SUF group. Abbreviation: nc, before induction.

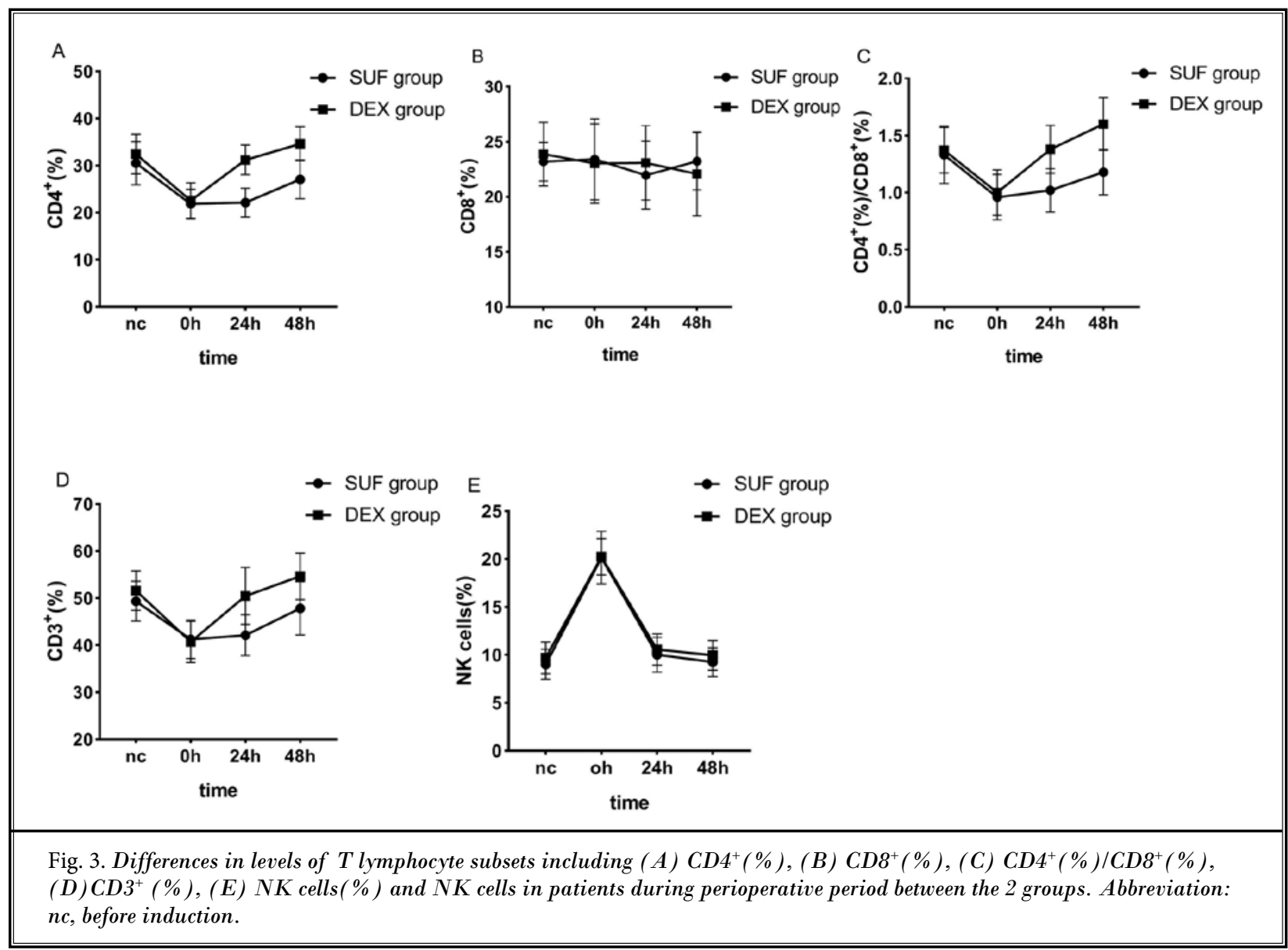



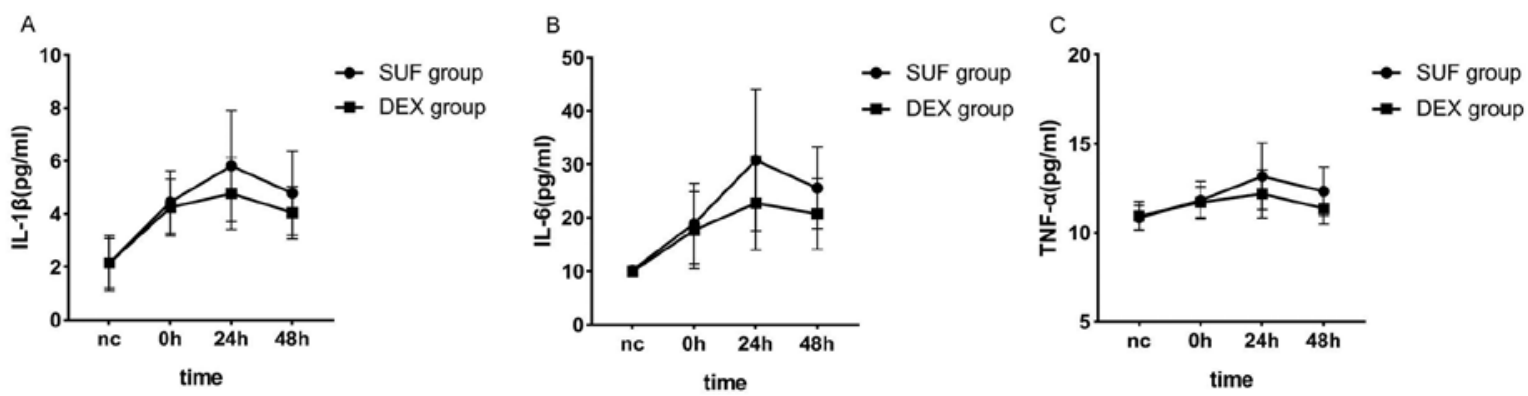

Fig. 4. Differences in levels of cytokine (A) IL-1 $\beta$, (B) IL-6, (C) TNF- $\alpha$ in patients during perioperative period between the 2 groups. Abbreviation: nc, before induction.

Table 4. Changes in levels of T lymphocyte subsets and NK cells in patients during perioperativeperiod between 2 groups(mean \pm $S D)$.

\begin{tabular}{|c|c|c|c|c|c|c|}
\hline$\overline{\text { Group }}$ & Time & $\mathrm{CD3}^{+} \mathrm{T}(\%)$ & $\mathrm{CD4}^{+} \mathrm{T}(\%)$ & $\mathrm{CDB}^{+} \mathrm{T}(\%)$ & $\mathrm{CD4}^{+} \mathrm{T} / \mathrm{CD8}^{+} \mathrm{T}$ & NK cells(\%) \\
\hline \multirow[t]{4}{*}{ SUF group } & $\mathrm{T}_{0}$ & $54.20 \pm 9.15$ & $32.47 \pm 4.55$ & $24.51 \pm 6.16$ & $1.39 \pm 0.33$ & $9.02 \pm 1.58$ \\
\hline & $\mathrm{T}_{1}$ & $45.25 \pm 7.82^{\mathrm{a}}$ & $21.85 \pm 3.13^{\mathrm{a}}$ & $23.82 \pm 6.73$ & $0.99 \pm 0.30^{\mathrm{a}}$ & $18.81 \pm 4.89^{\mathrm{a}}$ \\
\hline & $\mathrm{T}_{4}$ & $46.18 \pm 10.93^{\mathrm{a}}$ & $22.13 \pm 3.06^{\mathrm{a}}$ & $23.46 \pm 8.29$ & $1.04 \pm 0.33^{\mathrm{a}}$ & $10.03 \pm 1.82$ \\
\hline & $\mathrm{T}_{5}$ & $52.53 \pm 8.77$ & $30.90 \pm 3.81$ & $24.51 \pm 6.50$ & $1.32 \pm 0.28$ & $9.27 \pm 1.50$ \\
\hline \multirow[t]{4}{*}{ DEX group } & $\mathrm{T}_{0}$ & $56.49 \pm 8.51$ & $34.34 \pm 4.27$ & $24.52 \pm 6.39$ & $1.47 \pm 0.34$ & $9.70 \pm 1.66$ \\
\hline & $\mathrm{T}_{1}$ & $44.44 \pm 10.60^{\mathrm{a}}$ & $22.57 \pm 3.77^{\mathrm{a}}$ & $23.40 \pm 8.21$ & $1.04 \pm 0.29^{\mathrm{a}}$ & $18.49 \pm 3.88^{\mathrm{a}}$ \\
\hline & $\mathrm{T}_{4}$ & $51.30 \pm 6.93^{\mathrm{ab}}$ & $28.43 \pm 3.43^{\mathrm{ab}}$ & $24.31 \pm 4.84$ & $1.21 \pm 0.23^{\mathrm{ab}}$ & $10.57 \pm 1.63$ \\
\hline & $\mathrm{T}_{5}$ & $57.29 \pm 7.95^{\mathrm{b}}$ & $34.61 \pm 3.60^{\mathrm{b}}$ & $24.19 \pm 5.67$ & $1.48 \pm 0.28^{\mathrm{b}}$ & $9.97 \pm 1.55$ \\
\hline
\end{tabular}

${ }^{\mathrm{a}}$ compared with that at $\mathrm{T}_{0}, P<0.05$; ${ }^{\mathrm{b}}$ compared with that in SUF group, $P<0.05$.

In this study, multimodal analgesia was employed, using different types of analgesics, such as opioids, NSAIDs, DEX, and tramadol, and intercostal nerve block (12).

DEX, as an adjuvant analgesic, is widely used to improve the patients' pain states, sedation, and sleep quality (13). Recently, DEX was added to opioid-based PCIA and proved to reduce opioids consumption and opioid-related adverse effects, provide stable hemodynamics, and effective postoperative analgesia $(14,15)$. One research studied the optimal dose of DEX combined with SUF in PCIA in patients undergoing spinal surgery. It was realized that $4.33 \mu \mathrm{g} / \mathrm{kg}$ of DEX combined with $3.0 \mu \mathrm{g} / \mathrm{kg}$ of SUF diluted in $250 \mathrm{~mL}$ normal saline solution for PCIA at an infusion rate of $4 \mathrm{~mL} / \mathrm{h}$ provided effective analgesia with no complications, such as bradycardia, hypotension, respiratory depression, or oversedation (16). Similar doses of DEX and SUF were employed in our study.

KET has toxicity effects on the Gl, renal, and blood systems, the risk factors of which include usage beyond
5 days, age beyond 65 years, and history of GI bleeding or ulceration (9). In several studies using KET for PCIA, a regimen with fewer complications was recommended (that is a bolus dose of $30 \mathrm{mg}$ followed by continuous infusion of $3.6 \mathrm{mg} / \mathrm{h} \mathrm{KET})(8,9)$.

In this study, both regimens provide sufficient analgesia with all the VAS scores $<4$ at any time point. There was no statistically significant difference in VAS scores, PCIA pressing times, and consumption of tramadol.

In the DEX group, patients had relatively stable hemodynamics with no severe cardiovascular complications, and the sedation effect was relatively better. DEX produces a similar sleep effect by acting on the alpha- 2 receptor of the plaque nucleus and stimulating the endogenous sleep-promoting pathway (13), which makes patients feel more comfortable.

Concerning complications, the incidence of nausea in the DEX group was lower, which may be because of the decreased dosage of SUF and the antiemetic effect 
of DEX (16). There was no significant difference in vomiting, oversedation, pruritus, and respiratory depression in both groups.

It is generally believed that IL-1 $\beta, \mathrm{IL}-6$, and TNF- $\alpha$ can influence the severity of inflammation to some extent. TNF- $\alpha$ usually rapidly increases in the early stage of the stress response, such as trauma, OLV, and IRI. It promotes the release of IL- 6 and initiates a continuous reaction of inflammation.

DEX can activate the alpha- 2 adrenergic receptor and consequently activate cholinergic transmitters to alleviate the stress response, thereby reducing the body's inflammatory response $(17,18)$. Also, DEX has an antiinflammatory effect by affecting immune cells directly or indirectly. Alpha-2 adrenergic stimulation transforms cytokine gene expression from a proinflammatory to an antiinflammatory profile (19). Moreover, DEX can reduce the levels of inflammatory factors such as IL-1 $\beta$, IL- 6 , and TNF- $\alpha$ by inhibiting the activation of $\mathrm{NF}-\kappa \mathrm{B} /$ Toll-like receptor signaling pathway (20).

In this study, the levels of serum IL-1 $\beta, \mathrm{IL}-6$, and TNF- $\alpha$ markedly increased after surgery, and ones in the DEX group were significantly lower than the SUF group at 24 and 48 hours after surgery. That may owe to the antiinflammatory effect of DEX on the recovery of the patients, which is similar to other studies.

NK cells, NKT cells, T lymphocyte helper cells (CD4+), and $\mathrm{T}$ cytotoxic lymphocytes $\left(\mathrm{CD}^{+}\right)$are concentrated functional cellular mediators of the immune system and play important roles in tumor cell-mediated immune responses. All mature T cells $\left(\mathrm{CD}^{+}\right)$can be divided into $\mathrm{CD}^{+}$and $\mathrm{CD}^{+}$cells. $\mathrm{CD} 4^{+}$cells could assist $\mathrm{CD} 8^{+}$to kill tumor cell (21), and $\mathrm{CD} 8^{+}$cells are mainly cytotoxic and inhibiting $\mathrm{T}$ cells (22). CD4 ${ }^{+} / \mathrm{CD}^{+}$is an important indicator for judging the body's immune function.

Our present data show that surgical trauma and anesthesia induce significant suppression changes in $\mathrm{CD}^{+}$, $\mathrm{CD}^{+}$, and $\mathrm{CD} 4^{+} / \mathrm{CD}^{+}$cells, which significantly decreased after surgery (23). The CD8+ levels were stable before and after surgery in both groups, which agreed with other reports $(23,24)$ indicating that the direct killing effect of $\mathrm{CD}^{+} \mathrm{T}$ cells on target cells was not significantly affected. $\mathrm{CD}^{+}, \mathrm{CD}^{+}$, and $\mathrm{CD} 4^{+} / \mathrm{CD}^{+}{ }^{+}$were decreased in the 2 groups at 24 and 48 hour period, but the SUF group decreased significantly. The probable reason was that DEX reduced the degree of immunosuppression by inhibiting the inflammatory response. The previous report shows that cytokines, such as IL-1 $\beta$, IL-6, and TNF- $\alpha$, from monocytes/macrophages and lymphocytes activated may stimulate the hypothalamic pituitary adrenal (HPA) (25), whereas the HPA-axis activation suppresses cell-mediated immunity $(26,27)$. Opioids are known to cause immunosuppression $(4,28)$. It has been proven that immune cells, including lymphocytes, NK cells, and macrophages, have opioid receptors on their surface. Immunosuppression either interact directly with opioid receptors on immune cells or receptors within the central nervous system $(29,30)$. Therefore we speculate that opioids consumption reduction to be another important reason for immunosuppression alleviation.

\section{Limitations}

The sample size in our study was quite small and only performed at one single center.

\section{Conclusions}

Our results suggested that whole-course application of DEX added to SUF or KET could sufficiently relieve pain, reduce opioid consumption, and postoperative nausea, and provide stable hemodynamics in postoperative analgesia. Moreover, the nonnarcotic regimen with DEX and KET could alleviate inflammatory response and immunosuppression in TSS. It is worthy of consideration, but more study is needed to recommend outright.

\section{Acknowledgment}

The authors thank all of the authors of previously published studies. 


\section{RefERENCES}

1. Howington JA, Blum MG, Chang AC, Balekian AA, Murthy SC. Treatment of stage I and II non-small cell lung cancer: Diagnosis and management of lung cancer, 3rd ed: American College of Chest Physicians evidence-based clinical practice guidelines. Chest 2013; $143(5$ Suppl):e278S-e313S.

2. Wang $\mathrm{H}$, Li S, Liang $\mathrm{N}$, Liu $\mathrm{W}$, Liu $\mathrm{H}$, $\mathrm{Liu} \mathrm{H}$. Postoperative pain experiences in Chinese adult patients after thoracotomy and video-assisted thoracic surgery. J Clin Nurs 2017; 26:2744-2754

3. Guo YB, Xu JD, Ji XX, Zhang JX, Liang JX, Zhou GB. Protective effect of dexmedetomidine against perioperative inflammation and on pulmonary function in patients undergoing radical resection of lung cancer. Nan Fang Yi Ke Da Xue Bao 2017; 37:1673-1677.

4. Cata JP, Keerty $V$, Keerty D, et al. A retrospective analysis of the effect of intraoperative opioid dose on cancer recurrence after non-small cell lung cancer resection. Cancer Med 2014; 3:900-908.

5. Plein LM, Rittner HL. Opioids and the immune system-friend or foe. $\mathrm{Br}$ J Pharmacol 2018; 175:2717-2725.

6. Wang $\mathrm{K}, \mathrm{Li} \mathrm{C}$. Effects of dexmedetomidine on inflammatory factors, $T$ lymphocyte subsets and expression of NF- $\mathrm{KB}$ in peripheral blood mononuclear cells in patients receiving radical surgery of colon carcinoma. Oncol Lett 2018; 15:7153-7157.

7. Song $\mathrm{P}$, Dong $\mathrm{T}$, Zhang J, Li J, Lu W. Effects of different methods of anesthesia and analgesia on immune function and serum tumor marker levels in critically ill patients. Exp Ther Med 2017; 14:2206-2210.

8. Howard ML, Isaacs AN, Nisly SA. Continuous infusion nonsteroidal antiinflammatory drugs for perioperative pain management. J Pharm Pract 2018; 31:66-81.

9. Schwinghammer AJ, Isaacs AN, Benner RW, Freeman H, O'Sullivan JA, Nisly SA. Continuous infusion ketorolac for postoperative analgesia following unilateral total knee arthroplasty. Ann Pharmacother 2017; 5:451-456.

10. Vallejo R, Hord ED, Barna SA, SantiagoPalma J, Ahmed S. Perioperative immunosuppression in cancer patients. J Environ Pathol Toxicol Oncol 2003; 22:139-146.
11. Snyder GL, Greenberg S. Effect of anaesthetic technique and other perioperative factors on cancer recurrence. $\mathrm{Br} J$ Anaesth 2010; 105:106-115.

12. Kolettas A, Lazaridis G, Baka S, et al. Postoperative pain management. J Thorac Dis 2015; 7(Suppl 1):S62-S72.

13. Ip HY, Abrishami A, Peng PW, Wong J, Chung F. Predictors of postoperative pain and analgesic consumption: A qualitative systematic review. Anesthesiology 2009; 111:657-677.

14. Peng K, Zhang J, Meng XW, Liu HY, Ji $\mathrm{FH}$. Optimization of postoperative intravenous patient-controlled analgesia with opioid-dexmedetomidine combinations: An updated metaanalysis with trial sequential analysis of randomized controlled trials. Pain Physician 2017; 20:569-596.

15. Dong CS, Lu Y, Zhang J, et al. The optimal dose of dexmedetomidine added to an sufentanil-based analgesic regimen for postoperative pain control in spine surgery: A probit analysis study. Medicine (Baltimore) 2016; 95:e4776.

16. Song Y, Shim JK, Song JW, Kim EK, Kwak YL. Dexmedetomidine added to an opioid-based analgesic regimen for the prevention of postoperative nausea and vomiting in highly susceptible patients: A randomised controlled trial. Eur J Anaesthesiol 2016; 33:75-83.

17. Klimscha W, Tong C, Eisenach JC. Intrathecal alpha2-adrenergic agonists stimulate acetylcholine and norepinephrine release from the spinal cord dorsal horn in sheep. An in vivo microdialysis study. Anesthesiology 1997; 87:110-116.

18. Xiang $\mathrm{H}, \mathrm{Hu}$ B, Li Z, Li J. Dexmedetomidine controls systemic cytokine levels through the cholinergic anti-inflammatory pathway. Inflammation 2014; 37:1763-1770.

19. Romero-Sandoval EA, McCall C, Eisenach JC. Alpha2-adrenoreceptor stimulation transforms immune responses in neuritis and blocks neuritis-induced pain. J Neurosci 2005; 25:8988-8994.

20. Li B, Li $\mathrm{Y}$, Tian $\mathrm{S}$, et al. Antiinflammatory effects of perioperative dexmedetomidine administered as an adjunct to general anesthesia: A metaanalysis. Sci Rep 2015; 5:12342.

21. Ghiringhelli F, Larmonier N, Schmitt
E, et al. $C_{4}+C_{25}+$ regulatory cells suppress tumor immunity but are sensitive to cyclophosphamide which allows immunotherapy of established tumors to be curative. Eur ] Immunol 2004; 34:336-344.

22. Feng $\mathrm{Q}$, Wei $\mathrm{H}$, Morihara J, et al. Th2 type inflammation promotes the gradual progression of HPV-infected cervical cells to cervical carcinoma. Gynecol Oncol 2012; 127:412-419.

23. Cata JP, Bauer M, Sokani T, et al. Effects of surgery, general anesthesia, and perioperative epidural analgesia on the immune function of patients with nonsmall cell lung cancer. J Clin Anesth 2013; 25:255-262.

24. Greenfeld K, Avraham R, Benish M, et al. Immune suppression while awaiting surgery and following it: Dissociations between plasma cytokine levels, their induced production and NK cell cytotoxicity. Brain Behav Immun 2007; 21:503-513.

25. Kennedy BC, Hall GM. Neuroendocrine and inflammatory aspects of surgery: Do they affect outcome? Acta Anaesthesiol Belg 1999; 50:205-209.

26. Bernabé DG, Tamae AC, Biasoli ÉR, Oliveira SH. Stress hormones increase cell proliferation and regulates interleukin-6 secretion in human oral squamous cell carcinoma cells. Brain Behav Immun 2011; 25:574-583.

27. Yang EV, Kim SJ, Donovan EL, et al. Norepinephrine upregulates VEGF, IL8, and IL-6 expression in human melanoma tumor cell lines: Implications for stress-related enhancement of tumor progression. Brain Behav Immun 2009; 23:267-275.

28. Gong L, Qin Q, Zhou L, et al. Effects of fentanyl anesthesia and sufentanil anesthesia on regulatory $T$ cells frequencies. Int J Clin Exp Pathol 2014; 7:7708-7716.

29. Lysle DT, Coussons ME, Watts VJ. Morphine-induced modulation of immune status: Evidence for opioid receptor mediation and compartment specificity. Adv Exp Med Biol 1993; 335:53-59.

30. Weber RJ, Pert A. The periaqueductal gray matter mediates opiate-induced immunosuppression. Science 1989; 245:188-190. 
